\title{
Deconstructing the DGAT1 Enzyme: Membrane Interactions at Substrate Binding Sites
}

\author{
Jose L. S. Lopes ${ }^{1}$, Leila M. Beltramini ${ }^{1}$, Bonnie A. Wallace ${ }^{2 *}$, Ana P. U. Araujo ${ }^{1 *}$ \\ 1 Instituto de Física de São Carlos, USP, São Carlos, Brazil, 2 Institute of Structural and Molecular Biology, \\ Birkbeck College, University of London, London, United Kingdom \\ *anapaula@ifsc.usp.br (APUA); b.wallace@mail.cryst.bbk.ac.uk (BAW)
}

\section{Abstract}

Diacylglycerol acyltransferase 1 (DGAT1) is a key enzyme in the triacylglyceride synthesis pathway. Bovine DGAT1 is an endoplasmic reticulum membrane-bound protein associated with the regulation of fat content in milk and meat. The aim of this study was to evaluate the interaction of DGAT1 peptides corresponding to putative substrate binding sites with different types of model membranes. Whilst these peptides are predicted to be located in an extramembranous loop of the membrane-bound protein, their hydrophobic substrates are membrane-bound molecules. In this study, peptides corresponding to the binding sites of the two substrates involved in the reaction were examined in the presence of model membranes in order to probe potential interactions between them that might influence the subsequent binding of the substrates. Whilst the conformation of one of the peptides changed upon binding several types of micelles regardless of their surface charge, suggesting binding to hydrophobic domains, the other peptide bound strongly to negatively-charged model membranes. This binding was accompanied by a change in conformation, and produced leakage of the liposome-entrapped dye calcein. The different hydrophobic and electrostatic interactions observed suggest the peptides may be involved in the interactions of the enzyme with membrane surfaces, facilitating access of the catalytic histidine to the triacylglycerol substrates. unrestricted use, distribution, and reproduction in any medium, provided the original author and source are credited.

Data Availability Statement: All relevant data are within the paper and its Supporting Information files.

Funding: This work was supported by a fellowship from São Paulo Research Foundation (FAPESP) to JLSL, grants 2009/17698-5 and 2010/13036-5; and grants H023852 and J019135 from the UK Biotechnology and Biological Sciences Research Council (BBSRC) (to BAW); and paired UK-Brazil partnering grants from the BBSRC (to BAW grant J019747) and Brazil National Council of Technological and Scientific Development (CNPq) to APUA, grants 553056/2011-5 and 407337/2013-0.

\section{Introduction}

Diacylglycerol acyltransferase (DGAT) is an enzyme that catalyses the esterification of a 1,2-diacylglycerol with a fatty acyl-CoA [1], resulting in a triacylglycerol (TAG) molecule in a reaction that is known to be the main limiting step in the TAG synthesis pathway [2].

Homologous DGAT1 genes have been identified in a wide range of eukaryotic organisms, including yeast, plants, fungi, invertebrates and mammals. In tobacco, DGAT1 gene silencing reduced by $\sim 50 \%$ the oil content of mature seeds [3]. In Drosophila, the DGAT1 gene was identified as causing premature apoptosis [4]. In humans, in addition to the clinical interest in the DGAT1 enzyme as a target for obesity treatment [5-7], studies have found related roles for this 
Access to the Synchrotron Radiation Circular Dichroism (SRCD) beamlines at ISA (Aarhus, Denmark) and ANKA (Karlsruhe, Germany) was enabled by beamtime grants (to BAW and JLSL). The funders had no role in study design, data collection and analysis, decision to publish, or preparation of the manuscript.

Competing Interests: The authors have declared that no competing interests exist. enzyme in many human disorders, such diabetes [8], nonalcoholic steatohepatitis [9] and insulin resistance [10]. In cattle, the DGAT1 is associated with the level of TAG deposited intramuscularly and with the regulation of the milk fat content and TAG composition [11, 12].

Little is known about the three-dimensional structure of DGAT1 enzymes as no crystal structures of these or any closely homologous proteins have yet been determined. DGAT1 appears to include multiple transmembrane segments [2]. Similarities with the acylcholesterol acyl-transferase (ACAT) enzymes have been used to predict the potential substrate binding sites of DGAT1 [13]. Studies with the plant Brassica napus suggest that a hydrophilic region in the enzyme N-terminus interacts with acyl-CoA [14]. Meanwhile, other studies with DGAT1 from mice suggested that the $\mathrm{N}$-terminal segment is able to specifically bind to different acylCoAs [15]. Bovine DGAT1 shares a conserved region with the ACAT enzymes [16], which also suggests a potential binding region for this substrate. Both these binding sites are proposed to lie within an extramembranous loop of the protein.

Substrate binding sites in bovine DGAT1 enzyme that are identical to portions of the ACAT and protein kinase $\mathrm{C}$ forms enzymes have been identified [17]. The diacylglycerol (DAG) binding site is located in a soluble extramembranenous loop of the protein, rather than in a transmembrane domain, suggesting it would interact with DAG headgroup on (or close to) the membrane surface [17, 18]. Synthetic peptides (Sit1 and Sit2) corresponding to these proposed substrate binding sites of bovine DGAT1 [17] were shown to interact with the substrates for triacylglycerol synthesis (DAGs and acyl-CoAs) which are present in the membrane. Consequently, it is proposed that the peptides would need to interact with the membrane, in order to access and present the substrates to the catalytic histidine [19] which is located in the same extramembranous loop. In this study, the Sit1 and Sit2 peptides, and a combined version of them into a single peptide, were examined in the presence of model membranes in order to probe whether an interaction between them could enable the binding of the substrates. The knowledge of the DGAT1 binding site structure and the determination of the factors that drive its access to the substrates, together with the identification of the main regions that are required for the enzyme activity will contribute to our understanding of its mechanism of action.

\section{Material and Methods}

\section{Peptide synthesis, purification and characterization}

Synthetic peptides (Sit1, Sit2 and Sit1\&2), designed based on the primary structure of the bovine DGAT1 (UniProt code Q8MK44), were obtained as described in Lopes et al [17].

\section{Liposome preparation}

The lipid composition of endoplasmic reticulum (ER) membranes consists of $~ 50 \%$ phosphatidyl choline (PC), 30\% phosphatidyl ethanolamine (PE) and 15\% (phosphatidyl serine (PS) and phosphatidyl inositol (PI)) $[20,21]$. These glycerophospholipids vary widely in both the length and saturation of their acyl chains. Different phospholipids were employed here as a simplified system to probe the interaction of the peptides. Large unilamellar vesicles (LUVs) of 1-palmitoyl-2-oleoyl-sn-glycerol-3-phosphate (POPA); 1-palmitoyl-2-oleoyl-sn-glycerol-3-phosphaethanolamine (POPE); 1-palmitoyl-2-oleoyl-glycero-3-phospho-rac-glycerol (POPG); 1-palmitoyl-2-oleoyl-sn-glycero-3-phosphocholine (POPC); 1,2-dipalmitoyl-sn-glycero-3[phospho-L-serine] (DPPS); 1,2-dipalmitoyl-sn-glycero-3-[phospho-rac-(1-glycerol)] (DPPG); 1,2-dipalmitoyl-sn-glycero-3-phosphocholine (DPPC) were prepared by solubilizing the phospholipids in a mixture of chloroform/methanol 4:1 (v/v); the solvent was then slowly evaporated under a $\mathrm{N}_{2}$ stream, yielding a dry lipid film that was subsequently submitted to a SpeedVac system for $2 \mathrm{~h}$. The dry lipids were hydrated with water (or the appropriate buffer), 
then vortexed and extruded through a polycarbonate filter to yield LUVs with an average diameter of $100 \mathrm{~nm}$ (determined by dynamic light scattering). All phospholipids were purchased from Avanti Polar Lipids.

\section{Synchrotron radiation circular dichroism (SRCD) and circular dichroism (CD) spectroscopy}

The SRCD spectra of the DGAT1 peptides ( $3 \mathrm{mM}$ ) were obtained on either the CD1 beamline at ISA synchrotron (Aarhus University, Denmark) or the CD12@ANKA beamline at the ANKA synchrotron (Karlsruhe, Germany). Spectra were collected as an average of 3 scans over the wavelength range from 280 to $170 \mathrm{~nm}$ with $1 \mathrm{~nm}$ step size and $2 \mathrm{~s}$ dwell time, at $25^{\circ} \mathrm{C}$, using demountable quartz Suprasil cells (Hellma Analytics, UK) with a $0.0009 \mathrm{~cm}$ pathlength for both samples and their cognate baselines. CDTool [22] software was used to process the SRCD data, including the averaging of the scans, subtraction of the baseline, smoothing with a Savitsky-Golay filter and calibration versus camphorsulfonic acid. The final spectra were expressed in delta epsilon units.

Conventional CD spectra measurements of the DGAT peptides $(50 \mu \mathrm{M})$ were recorded from 185 to $280 \mathrm{~nm}$ on a J-815 spectropolarimeter (Jasco Instruments, Tokyo, Japan) using a $0.1 \mathrm{~cm}$ pathlength rectangular quartz cuvette, as an average of 6 scans. The CD spectra were obtained in $20 \mathrm{mM}$ glycine- $\mathrm{HCl}(\mathrm{pH} 3.0) ; 20 \mathrm{mM}$ sodium phosphate (pH 7.0) and $20 \mathrm{mM}$ sodium phosphate ( $\mathrm{pH}$ 11.0) buffers, in the presence and absence of phospholipid vesicles at 50:1 lipid/ peptide molar ratios, or in the presence of detergent-either $10 \mathrm{mM}$ sodium dodecyl sulfate (SDS), $1 \mathrm{mM}$ N-hexadecyl-N, N-dimethyl-3-ammonio-1-propanesulfonate (HPS) or $1 \mathrm{mM}$ cetyltrimethylammonium bromide (CTABr).

\section{Intrinsic fluorescence}

Steady state fluorescence emission spectra of the DGAT1 peptides were obtained using an ISS K2 spectrofluorimeter (ISS Fluorescence, Analytical and Biomedical Instruments, Illinois, USA), at $25^{\circ} \mathrm{C}$ with a circulating water bath using a $1 \mathrm{~cm}$ pathlength rectangular quartz cuvette. Samples $(50 \mu \mathrm{M})$ were excited at $295 \mathrm{~nm}$ and the emission spectra recorded from 305 to 450 $\mathrm{nm}$, under the same conditions used in the CD analyses. Reference spectra were recorded and subtracted after each measurement.

\section{Liposome leakage assays}

The release of entrapped calcein in LUVs of POPG was measured to assess integrity of the lipid bilayers in the presence of the peptides. LUVs containing encapsulated probes were prepared as follows: dry POPG was dissolved in a mixture of chloroform/methanol (2:1) and the solvent was slowly removed by evaporation in the presence of $\mathrm{N}_{2}$ to form a thin lipid film, followed by lyophilization for $1 \mathrm{~h}$. Lipid films were resuspended in 5 mM HEPES ( $\mathrm{pH}$ 7.4) containing 35 $\mathrm{mM}$ calcein, submitted to a series of 10 freeze/thaws cycles and extruded 11 times using polycarbonate filters (Nucleopore) with $100 \mathrm{~nm}$ pore diameters. These vesicles were applied onto a Sephadex G-75 column and eluted with $5 \mathrm{mM}$ HEPES (pH 7.4) containing $100 \mathrm{mM} \mathrm{NaCl}$ to remove the unencapsulated calcein. The LUV suspension was diluted in 5 mM HEPES (pH 7.4) containing $100 \mathrm{mM} \mathrm{NaCl}$ to give a final lipid concentration of $0.1 \mathrm{mM}$. The final concentration of phospholipid was determined by phosphorus analysis [23]. Different amounts of the peptides were added to the cuvette and the extent of leakage was measured at different peptide: lipid molar ratios. Fluorescence intensities were recorded at $25^{\circ} \mathrm{C}$ with continuous stirring. Measurements were performed as a function of time with excitation at $490 \mathrm{~nm}$ and emission at 
$520 \mathrm{~nm}$. The percentage of leakage was calculated by using the following equation:

$$
\%_{\text {Leakage }}=\frac{\left(F-F_{0}\right)}{\left(F_{100}-F_{0}\right)} \times 100,
$$

where $F_{0}$ is the initial fluorescence intensity of vesicles, $F$ is the fluorescence intensity after adding the peptide, and $F_{100}$ is the fluorescence after addition of Triton X-100 (to completely solubilize and disrupt the LUVs).

\section{Surface plasmon resonance}

Biosensor experiments were carried out using a BIAcore $\mathrm{X}$ analytical system (GE Healthcare) with an L1 sensorchip. The immobilization of the phospholipids was performed as follows: Firstly, N-octyl-LD-glucopyranoside $(40 \mathrm{mM})$ was used to clean the sensorchip surface. Then, DPPG LUVs (1 mM, diameter $100 \mathrm{~nm}$ ) were injected onto the sensorchip surface for $50 \mathrm{~min}$, with a $1 \mu \mathrm{l} / \mathrm{min}$ flow, at $25^{\circ} \mathrm{C}$. After this time, the flow was increased to $100 \mu \mathrm{l} / \mathrm{min}$ for $10 \mathrm{~min}$, and $4 \mathrm{mM} \mathrm{NaOH}$ was injected into the cell for $1 \mathrm{~min}$, with a $5 \mu \mathrm{l} / \mathrm{min}$ flow. Finally, bovine serum albumin $(1.5 \mu \mathrm{M})$ was injected in order to eliminate nonspecific interactions. Peptides (from $0.15 \mu \mathrm{M}$ to $100 \mu \mathrm{M}$ ) were then injected and their interactions with the bilayer were monitored for $10 \mathrm{~min}$, with a $20 \mu \mathrm{l} / \mathrm{min}$ flow rate. The sensorgrams were analyzed with the BIAevaluation software Version 4.1. The running buffer was $10 \mathrm{mM}$ HEPES (pH 7.4) with $\mathrm{NaCl}$ $(150 \mathrm{mM})$ and EDTA $(1 \mathrm{mM})$, and the regeneration solution was $\mathrm{NaOH}(10 \mathrm{mM})$. All solutions were freshly prepared and degassed prior to use.

\section{Results and Discussion}

\section{Conformations of DGAT1 peptides in solution}

The SRCD spectra of the peptides in aqueous solution, (Fig. 1) were consistent with a predominantly unordered secondary structures for all three isolated peptides in solution, as indicated by their negative peaks at $200 \mathrm{~nm}[24,25]$ and small positive peaks around $182 \mathrm{~nm}$. In the SRCD spectrum of Sit1, the presence of multiple adjacent aromatic residues Trp appears to give rise to a peak with a minimum at $228 \mathrm{~nm}$ (suggestive of exciton coupling of aromatic residues), in a similar way to antimicrobial peptide tritrpticin [26], a 13 residue peptide with adjacent Trp residues (VRRFPWWWPFLRR). The high flux of the SRCD spectroscopy has greatly improved the signal-to-noise ratio in the data, reducing the differences between the replicates. Analysis of the errors bars with the individual scans and the replicates of the CD/SRCD measurements have indicated only small deviations on each sample even at the low wavelength region.

The fluorescence emission spectra of these peptides in aqueous solution confirmed the exposure of the Trp residues to the aqueous environment, since maximum emission was centered at $354 \mathrm{~nm}$, a wavelength corresponding to the Trp emission when free in aqueous solution [27].

Only small differences in the CD spectra were observed when the peptides were incubated at different pHs from 3.0 to 11.0 (S1 Fig.), and likewise, no displacement of the fluorescence maximum emission was observed as a function of $\mathrm{pH}$. However, quenching was noted at the pH 3.0 (S1 Fig.), which could be explained by the protonation of the histidine residues in Sit2 at acid $\mathrm{pH}$, as they could act as strong fluorescence quenchers, with a charge transfer between the indole and the imidazole ring when they approach each other. 


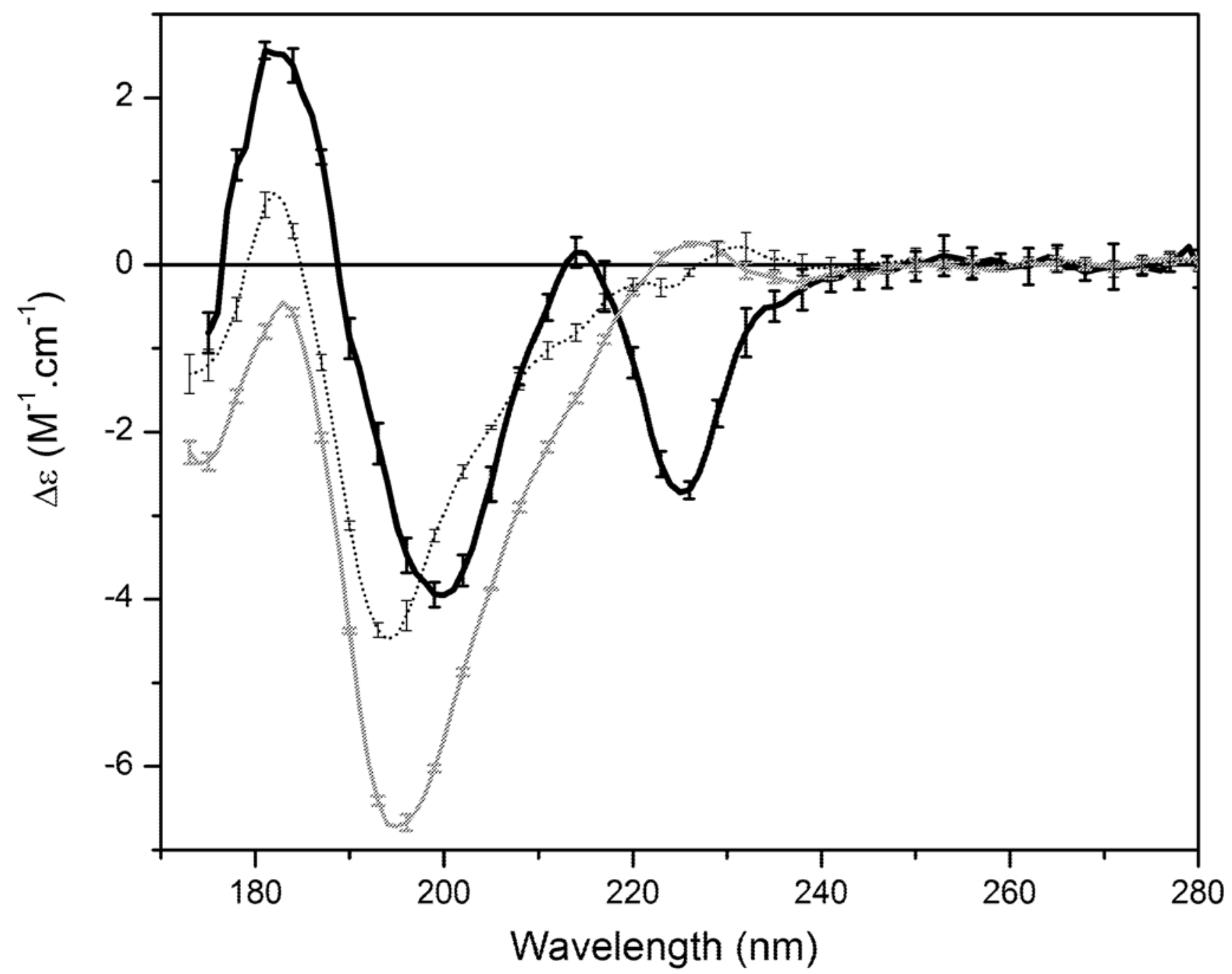

Fig 1. SRCD spectra of DGAT1 peptides. Sit1 (black), Sit2 (grey) and Sit1\&2 (dot) in $20 \mathrm{mM}$ Sodium Phosphate buffer (pH 7.0). Error bars represent one standard deviation in the replicate measurements.

doi:10.1371/journal.pone.0118407.g001

\section{Interactions with model membranes}

In order to investigate the interaction of DGAT1 peptides with the model membranes, peptides were incubated with detergent or phospholipid vesicles. Initially, zwitterionic, and negativelyand positively- charged surfactants (SDS, HPS and CTABr, respectively) were used to examine whether the head group net charge could favor interaction with any of the peptides.

The CD spectrum of the peptide Sit 1 exhibited a conformational change, indicated by the presence of new spectral minima at $208 \mathrm{~nm}$ (Fig. 2a) in the presence of all the three detergents. In agreement with the $\mathrm{CD}$ data, a blue shift was observed in the fluorescence maximum emission of Sit1 in the presence of all the detergents (Fig. 2b), changing from 354 to $337 \mathrm{~nm}$. This suggests the aromatic sidechains of the Trp residues are less exposed to the aqueous environment and perhaps are accessible to the hydrophobic core of the detergent micelles.

The CD spectra of the peptide Sit2 showed a dependence on the nature of the hydrophilic head group component of the detergents, with the most prominent conformational change 

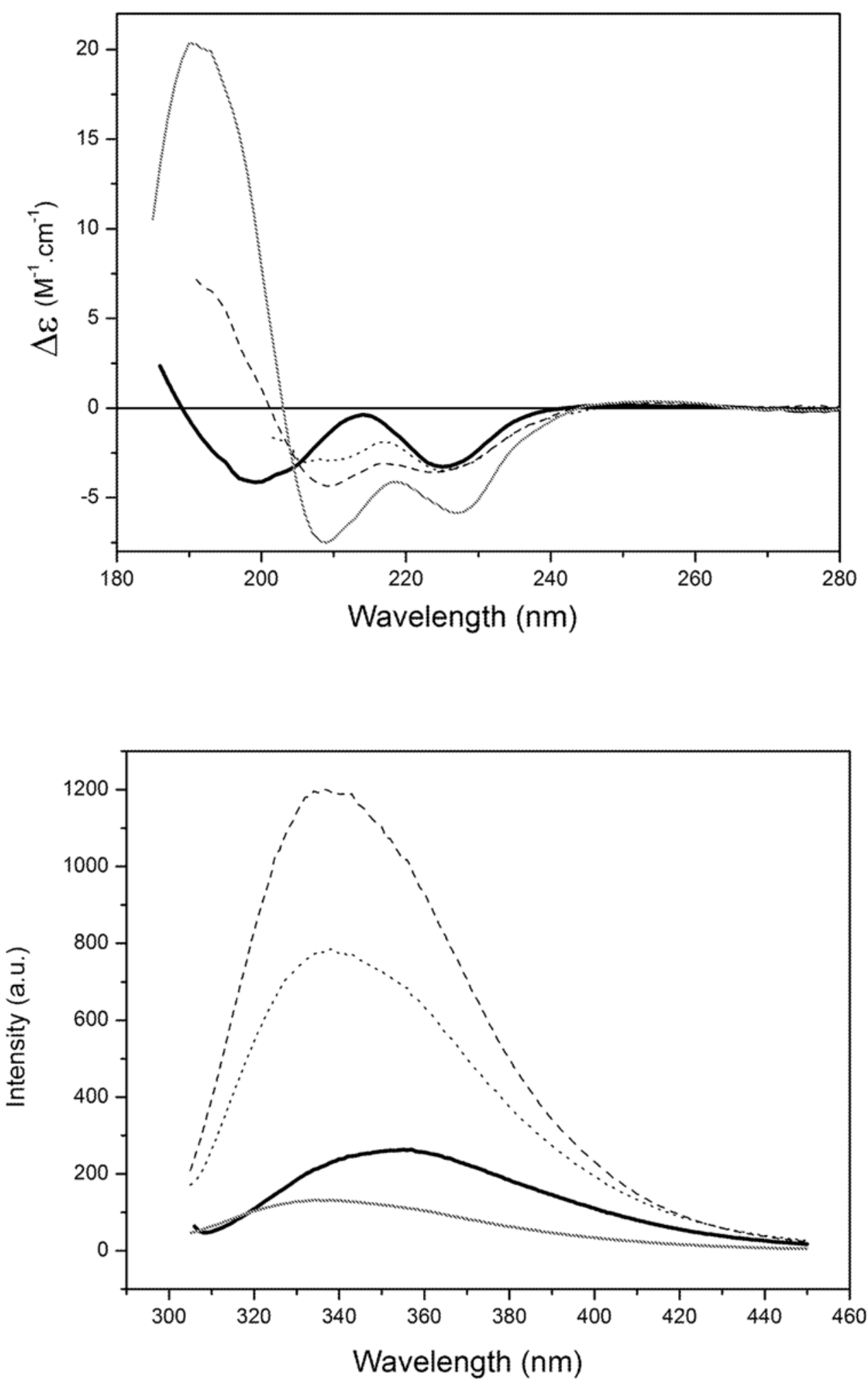

Fig 2. Interactions of the Sit1 peptide with different types of model membranes. a) CD spectroscopy Sit1 in the presence of micelles composed of HPS (dash), CTAB (dot), and SDS (grey), compared with the peptide in aqueous solution (black). b) Emission spectra of Sit1 in aqueous solution (black) and in the presence of HPS (dash), CTAB (dot), and SDS (grey) detergents.

doi:10.1371/journal.pone.0118407.g002 
occurring in the presence of the SDS (S2 Fig.), producing peaks at 206 and $222 \mathrm{~nm}$, and a low intensity positive band at $195 \mathrm{~nm}$. Only very minor spectral changes were observed for Sit 2 with the positively-charged surfactant, suggesting a lack of interaction. In the presence of the zwitterionic HPS micelles, a decrease of the intensity of the peak at $198 \mathrm{~nm}$ and a small increase of the band at $222 \mathrm{~nm}$, might suggest a slightly more ordered net structure for Sit 2 than it was in aqueous solution.

The fluorescence spectra of Sit 2 in the presence of the detergents also indicate a clear interaction between the peptide and the negatively-charged detergents, with a blue shift in the $\lambda_{\max }$ to $331 \mathrm{~nm}$ suggesting a sequestering of the aromatic residues from interactions with the solvent. A blue shift was also seen when Sit2 was incubated with the HPS micelles, in agreement with the changes observed by $\mathrm{CD}$. The increase in the fluorescence intensity observed for peptides with HPS suggests it interacts differently from the other zwitterionic surfactants due to the higher degree of hydration of its polar head groups [28, 29]. Finally, for Sit2, essentially no binding was detected in the positively-charged micelles (CTAB) by the fluorescence assays, probably due to the repulsion of the peptide with its basic $\mathrm{pI}$ from the positive surface of the micelle (S2 Fig.), in agreement with the CD results.

The interaction of Sit1\&2 with micelles followed a pattern similar to that observed for Sit2 (S2 Fig.), indicating involvement of charge interactions between peptide and detergents, which result in conformational changes in the peptide structure.

In order to evaluate the interaction of the peptides with lipids, LUVs comprised of phospholipids with different head groups and fatty acid tails were incubated with the DGAT1 peptides. The interaction of Sit1 with the phospholipids presented a different behavior from that observed with the detergents. No significant changes in the CD spectra of Sit1 were observed when it was incubated with either zwitterionic or charged vesicles, producing similar spectra to those found in aqueous solution (S3 Fig.). It seems probable that the access of the peptide Sit1 to the acyl chains region was prevented, since this hydrophobic region in the liposomes is not as easily accessible as in micelles.

Sit2 also exhibited no alteration of its CD spectrum when incubated with zwitterionic LUVs. However, its CD spectrum changed considerably in the presence of negatively-charged LUVs (PG and PA) (Fig. 3a). Additionally, a blue shift of $15 \mathrm{~nm}$ was observed in the $\lambda_{\max }$ of the Sit2 fluorescence spectrum (Fig. 3b), also suggesting the microenvironment of this peptide was altered in the presence of negatively-charged membranes. This interaction may have been induced by the electrostatic attraction with positively-charged residues on the peptide.

The interaction of Sit1\&2 with LUVs (S4 Fig.) was very similar to that for Sit2, with little alteration observed for the zwitterionic vesicles, but producing an altered CD spectrum (perhaps indicative of a more ordered net peptide structure) in the presence of the POPG negativelycharged LUVs; this is in agreement with the blue shift of the fluorescence $\lambda_{\max }$, indicating the aromatic residues are more sequestered from interactions with aqueous environment. Surprisingly, in the presence of the POPA LUVs, only a small shift of the peak at $198 \mathrm{~nm}$ of the CD spectrum was observed, suggesting only a modest change in the peptide structure. Negativelycharged PA presents a very small headgroup when compared to the other negatively-charged lipids (PGs or PCs), perhaps because this phospholipid produces a negative spontaneous curvature whereas $P G$ produces zero spontaneous curvature [30].

\section{Disruption of the membranes: Calcein leakage assays}

The purpose of these assays was to compare the ability of the DGAT1 peptides to disturb the integrity of the lipid bilayers formed by negatively-charged phospholipids. The kinetics of calcein release from POPG vesicles (S5 Fig.) differed for Sit1 and Sit2 peptides. The addition of 

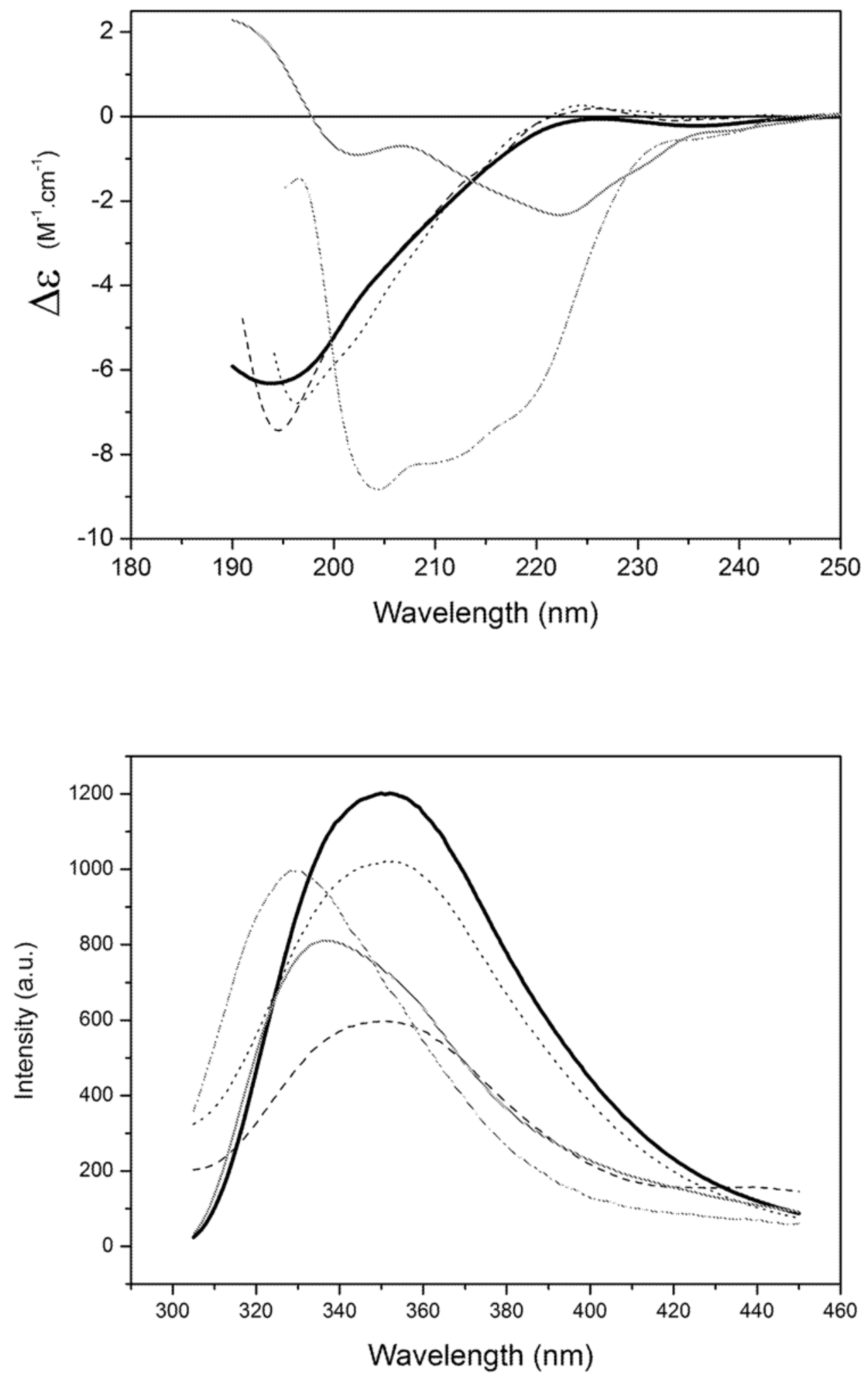

Fig 3. Interactions of the Sit2 peptide with different types of model membranes. a) CD spectra of Sit2 in aqueous solution (black) and in the presence of LUVs composed of different phospholipids (DPPS (dash), DPPC (dot), POPA (grey), and DPPG (dash dot grey)). b) Fluorescence spectra of Sit2 in aqueous solution (black) and in the presence of the different LUVs.

doi:10.1371/journal.pone.0118407.g003 


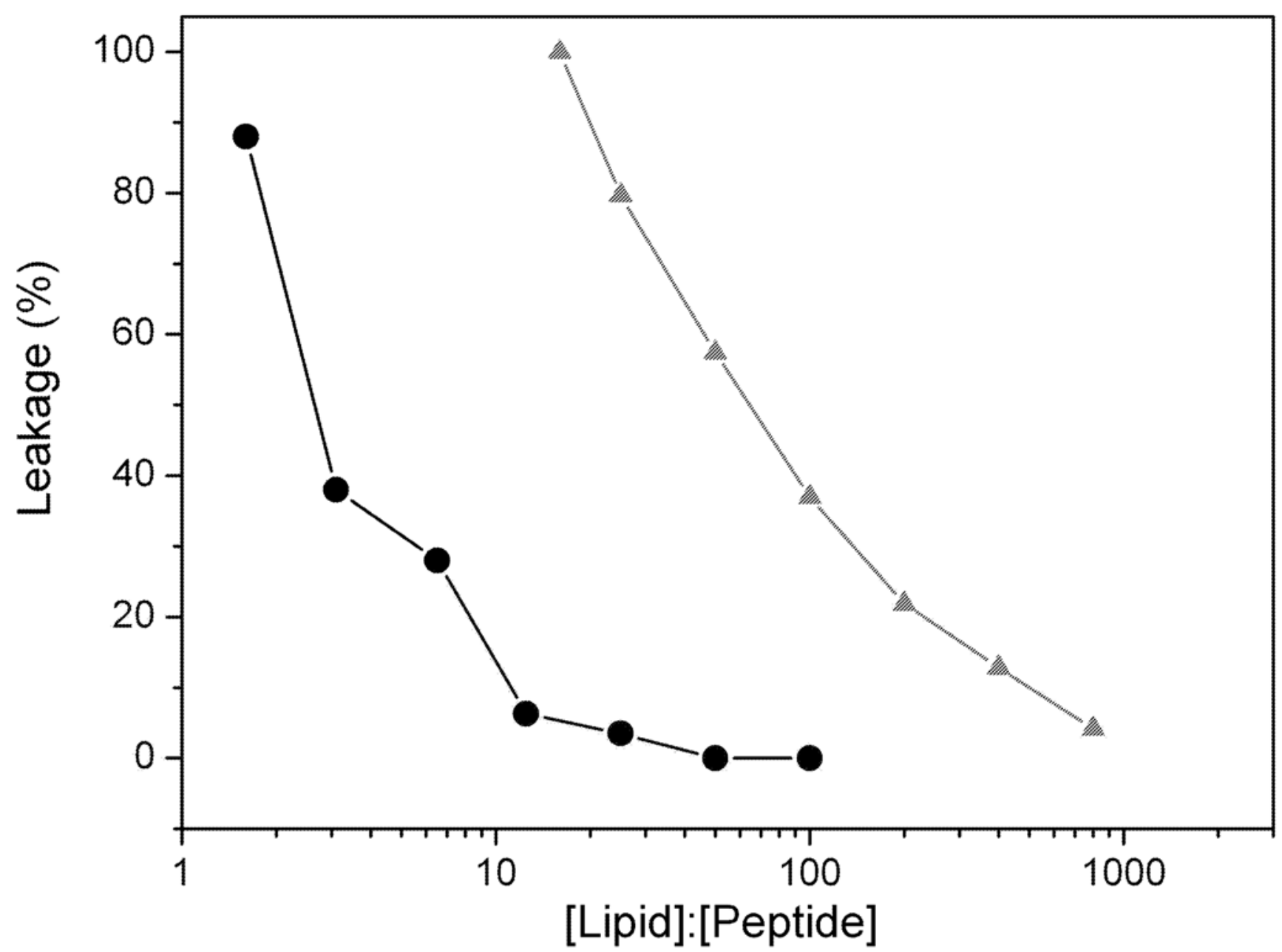

Fig 4. Integrity of LUVs in the presence of the peptides. Comparative leakage curves of Sit1 (black circles) and Sit2 (grey triangles) at different lipid: peptide molar ratios, after $10 \mathrm{~min}$ of incubation at $25^{\circ} \mathrm{C}$.

doi:10.1371/journal.pone.0118407.g004 

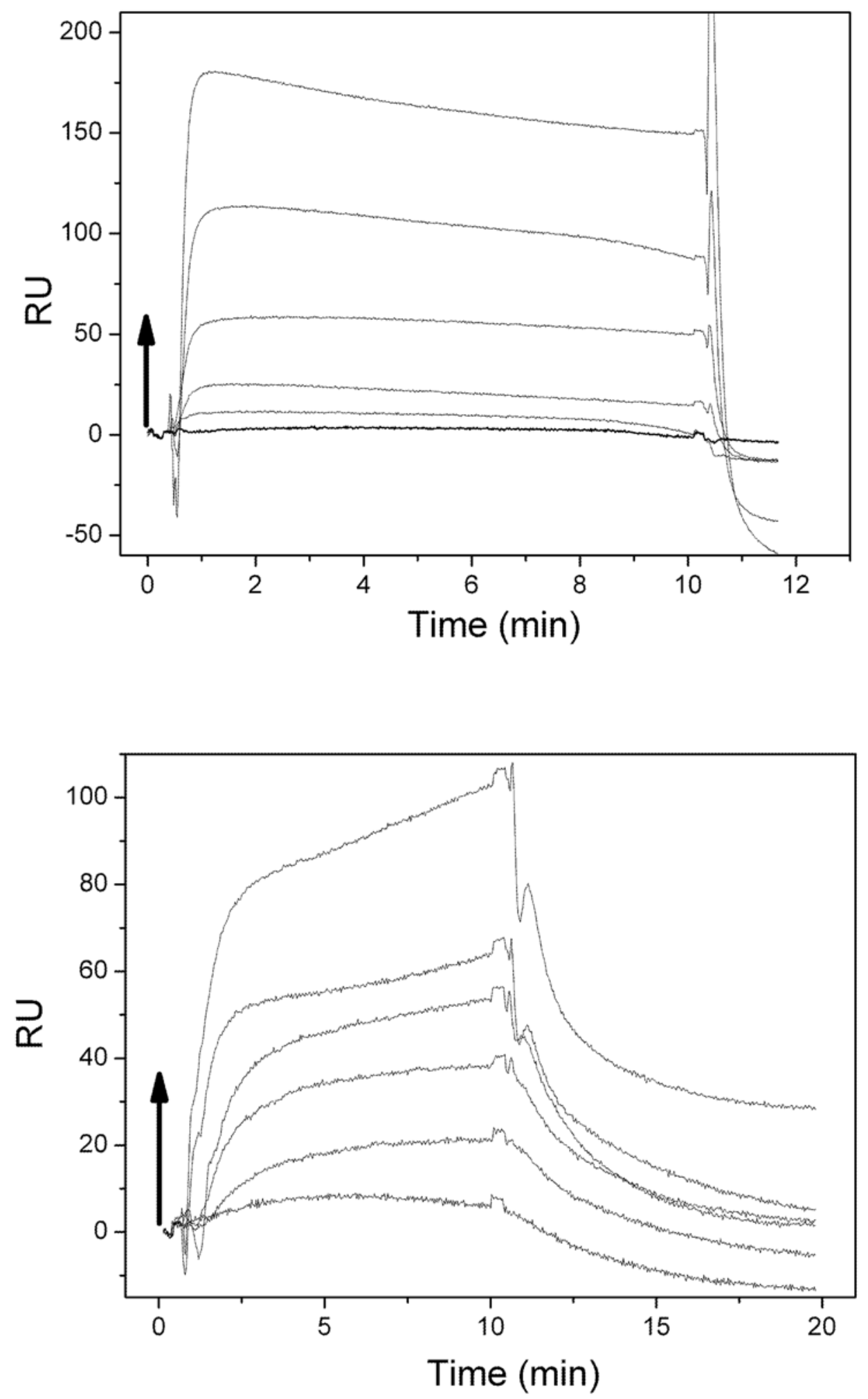

Fig 5. Surface plasmon resonance sensorgrams. a) Sit1 (at 0, 5, 10, 25, 50, and $100 \mu \mathrm{M}$ ) and b) Sit2 (at $0.15,0.31,0.62,1.25,2.5$, and $5 \mu \mathrm{M}$ ) on DPPG bilayers immobilized on a $\mathrm{L} 1$ sensorchip. The black arrows indicate the times of additions of peptide and the direction of the increase of peptide concentration.

doi:10.1371/journal.pone.0118407.g005 
with the negatively-charged liposomes, as had been observed using $\mathrm{CD}$ and fluorescence spectroscopies. For Sit2, however, the dissociation occurred more slowly, since the peptide was able to be efficiently bound to the negatively charged bilayer. According to the sensorgrams, the dissociation constants $\left(\mathrm{K}_{\mathrm{d}}\right)$ from the DPPG vesicles were calculated to be $170 \mu \mathrm{M}$ and $0.43 \mu \mathrm{M}$ for Sit 1 and Sit2, respectively. The stronger interaction of Sit 2 with negatively-charged surfaces suggest that charge interactions can play a role in modulating the binding of this segment of the DGAT1 enzyme to the substrates and/or the biologic membranes. Therefore, the presence of charged domains in biological cell membranes could trigger the attraction of the segments from the external loop of the DGAT1 protein to the membrane surface, where the substrates for triacylglycerol synthesis are localized.

\section{Conclusions}

The use of the model membrane systems allowed us to distinguish between different modes of interaction of the predicted peptides involved in DGAT1 activity. One of the binding sites (Sit1) appears to involve interactions with the lipid acyl chains of fluid model membranes, which allows the access of the peptide to the hydrophobic core of the system, while in the other binding site (Sit2), may involve an electrostatic attraction to negatively-charged membranes head groups. Nevertheless, the interactions of the putative binding sites in the intact DGAT1 enzyme are likely to be more complicated than those of the isolated model peptides examined in this study, since their local environment, net charge, or position within the enzyme could influence their ability to interact with membrane bilayer. This may be especially true for the region represented by the Sit2 peptide, where its net charge may bias its ability to bind to specific types of head groups. However, the information provided by this study regarding peptides representing proposed binding sites of the DGAT1 enzyme in the presence of lipid systems (membranes and substrates) do provide new insights about this important enzyme and its interactions. Since these peptides correspond to the predicted binding sites of the two substrates of DGAT1, knowledge of the factors that govern their ability to undergo conformational changes provide some new clues about how the enzyme's activity can be modulated.

Given the DGAT1 enzymes represent interesting therapeutic targets in obesity [5-7], insulin resistance [10,31], and in hepatitis C virus infection [32], it is important that DGAT1 structure-activity relationships are characterized, especially in the absence of any crystal structure of this enzyme or a close homologue. The information provided by this study on synthetic peptide corresponding to substrate binding sites should therefore contribute to understanding of the functioning of theses enzymes in metabolic disorders [33], and the development of novel inhibitors [34].

\section{Supporting Information}

S1 Fig. Minimal effect of $\mathbf{p H}$ on the structure of the DGAT1 peptides. CD spectra of a) Sit1, b) Sit2 and c) Sit1\&2 in pH 3.0 (dash), pH 7.0 (bold) and pH 11 (dot). Fluorescence spectra of

d) Sit1, e) Sit2 and f) Sit1\&2. Excitation was performed at $295 \mathrm{~nm}$, and emission was monitored from 305 to $450 \mathrm{~nm}$.

S2 Fig. Interactions of peptides with detergents. CD spectra of a) Sit2 and b) Sit1\&2 in water (black), in the presence of the detergents HPS (dash), CTAB (dot), and SDS (grey). Fluorescence spectra of c) Sit2 and d) Sit1\&2 with the same detergents.

(TIF) 
S3 Fig. Interactions of the Sit1 peptide with LUVs. a) CD spectra of Sit1 in water (black) or with LUVs of DPPS (dash), POPC (dot), POPA (grey), DPPG (dash dot grey), and POPG (dash dot dot grey). b) Fluorescence spectra of Sit1 (bold) in water or with LUVs of DPPS (dash), POPC (dot), POPA (grey), DPPG (dash dot grey), and POPG (dash dot dot grey). (TIF)

S4 Fig. Interactions of the Sit1\&2 peptide with LUVs. a) CD spectra of Sit1\&2 in water (black) or with LUVs of POPC (dash), POPE (dot), POPA (grey) and POPG (dash dot grey). b) Emission spectra of Sit1\&2 in water (black) or with LUVs of POPC (dash), POPE (dot), POPA (grey) and POPG (dash dot grey).

S5 Fig. Release of the internal contents from POPG liposomes. The addition of increasing amounts of a) Sit $1(8,16,32,32$, and $64 \mu \mathrm{M})$ and b) Sit2 $(0.125,0.25,0.5,1,2,4$, and $6 \mu \mathrm{M})$ gradually disturbs the liposome integrity. The arrows indicate the additions of peptide, and the bold curve is following addition of Triton-10\% detergent (after 10 min incubation), which completely disrupts the bilayer.

(TIF)

\section{Acknowledgments}

We thank N.C. Noronha for initial help in this work.

\section{Author Contributions}

Conceived and designed the experiments: JLSL LMB APUA BAW. Performed the experiments: JLSL. Analyzed the data: JLSL LMB BAW APUA. Contributed reagents/materials/analysis tools: BAW APUA. Wrote the paper: JLSL BAW APUA.

\section{References}

1. Coleman RA, Lewin TM, Muoio DM (2000) Physiological and nutritional regulation of enzymes of triacylglycerol synthesis. Annu Rev Nutr 20: 77-103. PMID: 10940327

2. Yen CLE, Stone SJ, Koliwad S, Harris C, Farese RV Jr (2008) DGAT enzymes and triacylglycerol biosynthesis. J. Lipid Res 49: 2283-2301. doi: 10.1194/jr.R800018-JLR200 PMID: 18757836

3. Zhang FY, Yang MF, Xu YN (2005) Silencing of DGAT1 in tobacco causes a reduction in seed oil content. Plant Science. 169: 689-694.

4. Buszczak M, Lu X, Segraves WA, Chang TY, Cooley L (2002) Mutations in the midway gene disrupt a Drosophila acyl coenzyme A: diacylglycerol acyltransferase. Genetics 160: 1511-1518. PMID: 11973306

5. Cheng D, Meegalla RL, He B, Cromley DA, Billheimer JT, Young PR (2001) Human acyl-CoA:diacylglycerol acyltransferase is a tetrameric protein. Biochem J 359: 707-714. PMID: 11672446

6. Chen HC, Farese RV Jr (2000) DGAT and triglyceride synthesis: a new target for obesity treatment? Trends Cardiovasc Med 10: 188-192. PMID: 11282293

7. Matsuda D, Tomoda H (2007) DGAT inhibitors for obesity. Curr Opin Investig Drugs 8: 836-841. PMID: 17907060

8. Subauste A, Burant CF (2003) DGAT: novel therapeutic target for obesity and type 2 diabetes mellitus. Curr Drug Targets Immune Endocr Metabol Disord 3: 263-270. PMID: 14683457

9. Villanueva CJ, Monetti M, Shih M, Zhou P, Watkins SM, Bhanot S, et al. (2009) Specific role for acyl CoA:Diacylglycerol acyltransferase 1 (Dgat1) in hepatic steatosis due to exogenous fatty acids. Hepatology 50: 434-442. doi: 10.1002/hep.22980 PMID: 19472314

10. Monetti M, Levin MC, Watt MJ, Sajan MP, Marmor S, Hubbard BK, et al. (2007) Dissociation of hepatic steatosis and insulin resistance in mice overexpressing DGAT in the liver. Cell Metab 6: 69-78. PMID: 17618857 
11. Grisart B, Coppieters W, Farnir F, Karim L, Ford C, Berzi P, et al. (2002) Positional candidate cloning of a QTL in dairy cattle: identification of a missense mutation in the bovine DGAT1 gene with major effect on milk yield and composition. Genome Res 12: 222-231. PMID: 11827942

12. Grisart B, Farnir F, Karim L, Cambisano N, Kim JJ, Kvasz A, et al. (2004) Genetic and functional confirmation of the causality of the DGAT1 K232A quantitative trait nucleotide in affecting milk yield and composition. Proc Natl Acad Sci USA 101: 2398-2403. PMID: 14983021

13. Cases S, Smith SJ, Zheng Y-W, Myers HM, Lear SR, Sande E, et al. (1998) Identification of a gene encoding an acyl CoA:diacylglycerol acyltransferase, a key enzyme in triacylglycerol synthesis. Proc Natl Acad Sci USA 95: 13018-13023. PMID: 9789033

14. Weselake RJ, Madhavji M, Szarka SJ, Patterson NA, Wiehler WB, Nykiforuk CL, et al. (2006) AcylCoA-binding and self-associating properties of a recombinant $13.3 \mathrm{kDa} \mathrm{N}$-terminal fragment of diacylglycerol acyltransferase-1 from oilseed rape. BMC Biochem. 7: 24. PMID: 17192193

15. Siloto RMP, Madhavji M, Wiehler WB, Burton TL, Boor PS, Weselake ARJ (2008) An N-terminal fragment of mouse DGAT1 binds different acyl-CoAs with varying affinity. Biochem Biophys Res Communn 373: 350-354. doi: 10.1016/j.bbrc.2008.06.031 PMID: 18571500

16. Talhari DT, Moraes ML, Castilho PV, Oliveira ON Jr, Beltramini LM, Araújo APU (2009) Interaction of a C-terminal peptide of Bos taurus diacylglycerol acyltransferase 1 with model membranes. Biochim Biophys Acta. 1788: 2320-2325. doi: 10.1016/j.bbamem.2009.07.023 PMID: 19664998

17. Lopes JLS, Nobre TM, Cilli EM, Beltramini LM, Araújo APU, Wallace BA (2014) Deconstructing the DGAT1 enzyme: binding sites and substrate interactions. Biochim. Biophys Acta Biomembranes. 1838: 3145-3152. doi: 10.1016/j.bbamem.2014.08.017 PMID: 25152299

18. Colón-González FI, Kazanietz MG. (2006) C1 domains exposed: from diacylglycerol binding to proteinprotein interactions. Biochim Biophys Acta. 1761: 827-837. PMID: 16861033

19. McFie PJ, Stone SL, Banman SL, Stone SJ (2010) Topological orientation of acyl-CoA:diacylglycerol acyltransferase-1 (DGAT1) and identification of a putative active site histidine and the role of the $n$ terminus in dimer/tetramer formation. J Biol Chem. 285: 37377-37387. doi: 10.1074/jbc.M110.163691 PMID: 20876538

20. Davison SC, Wills ED (1974) Studies on the lipid composition of the rat liver endoplasmic reticulum after induction with phenobarbitone and 20-methylcholanthrene. Biochem J 140: 461-468. PMID: 4447625

21. Meer G, Voelker DR, Feigenson GW (2008) Membrane lipids: where they are and how they behave. Nat Rev Mol Cell Biol 9: 112-124. doi: 10.1038/nrm2330 PMID: 18216768

22. Lees JG, Smith B, Wien F, Miles A, Wallace BA (2004) CDtool-an integrated software package for circular dichroism spectroscopic data processing, analysis, and archiving. Anal Biochem 332: 285-289. PMID: 15325297

23. Mcclare CW (1971) An accurate and convenient organic phosphorus assay. Anal. Biochem 39: 527-530. PMID: 4324534

24. Kelly SM, Jess TJ, Price NC (2005) How to study proteins by circular dichroism. Biochim. Biophys. Acta. 1751: 119-139. PMID: 16027053

25. Fasman GD (1996) Circular dichroism and the conformational analysis of biomolecules. Plenum. New York.

26. Schibli DJ, Hwang PM, Vogel HJ (1999) Structure of the antimicrobial peptide tritrpticin bound to micelles: a distinct membrane-bound peptide fold. Biochem 38: 16749-16755. PMID: 10606506

27. Lakowicz JR (2002) Topics in fluorescence spectroscopy. Protein fluorescence. Kluwer Academic Publishers. New York.

28. Moreira LM, Santiago PS, De Almeida EV, Tabak M (2008) Interaction of giant extracellular Glossoscolex paulistus hemoglobin ( $\mathrm{HbGp}$ ) with zwitterionic surfactant $\mathrm{N}$-hexadecyl- $\mathrm{N}, \mathrm{N}$-dimethyl-3-ammonio-1propanesulfonate (HPS): effects of oligomeric dissociation. Colloids Surf B Biointerfaces. 61: 153-163. PMID: 17825537

29. Baptista MS, Cuccovia IM, Chaimovich H, Politi MJ, Reed W (1992) Electrostatic properties of zwitterionic micelles. J Phys Chem 96: 6442-6449.

30. Dickey A, Faller R (2008) Examining the contributions of lipid shape and headgroup charge on bilayer behavior. Biophys J 95: 2636-2646. doi: 10.1529/biophysj.107.128074 PMID: 18515396

31. Birch AM, Buckett LK, Turnbull AV (2010) DGAT1 inhibitors as anti-obesity and anti-diabetic agents. Curr Opin Drug Discov Devel 13: 489-496. PMID: 20597032

32. DeVita RJ, Pinto S (2013) Current status of the research and development of diacylglycerol O-acyltransferase 1 (DGAT1) inhibitors. J Med Chem 56: 9820-9825. doi: 10.1021/jm4007033 PMID: 23919406 
33. Cao J, Zhou Y, Peng H, Huang X, Stahler S, Suri V, et al. (2011) Targeting Acyl-CoA:diacylglycerol acyltransferase 1 (DGAT1) with small molecule inhibitors for the treatment of metabolic diseases. J Biol Chem 268: 41838-41851.

34. Zhou G, Zorn N, Ting P, Aslanian R, Lin M, Cook J, et al. (2014) Development of novel benzomorpholine class of diacylglycerol acyltransferase I inhibitors. ACS Med Chem Lett 5: 544-549. doi: 10.1021/ ml400527n PMID: 24900877 